\title{
H.A.R.P.: investigating Mesolithic landscapes of life and death at the western edge of Europe
}

Aimée Little ${ }^{1, *}$, Ben Elliott ${ }^{2}$, Tracy Collins $^{3}$, Edward Blinkhorn $^{4}$,
Frank Coyne $^{3}$, Graeme Warren
${ }^{2}$, Gabriel Cooney ${ }^{2} \&$ Rick Schulting $^{5}$

Excavation at Hermitage, Ireland, revealed Early Mesolithic human cremation burials. One burial contained a stone adze, possibly used in a funerary rite and ritually blunted. The Hermitage Archaeological Research Project aims to identify the extent of mortuary activity, and to place these burials in their broader landscape context.

Keywords: Ireland, Mesolithic, cremation burial, geoarchaeology

Overlooking the River Shannon from atop a high bluff on its banks, the site of Hermitage holds a prominent place within the archaeological record of Ireland's earliest hunting-and -gathering communities (Figure 1). During the Early Mesolithic, successive generations of people returned here, leaving behind evidence of flint, shale and quartzite tools, the fires they lit and, crucially, their own ways of burying the dead.

Two, or possibly three, cremation pit burials were discovered in 2001 during commercial excavations by Ægis Archaeology Ltd in advance of sewage works (Collins \& Coyne 2003, 2006). A large area of burning identified near to the cremations may be the remnants of a pyre. Pit burial A (Figure 2) contained the well-cremated remains of an adult (Figure 3) and a postpipe feature, which is probably the traces of a grave marker. It also produced a discrete assemblage of grave goods: two small flint points and a large polished shale adze head. AMS dates from the human remains themselves and charcoal within the fill have produced dates of $8350 \pm 40 \mathrm{BP}$ (7530-7320 cal BC to 95.4\%; date modelled in OxCal v.4.3, using

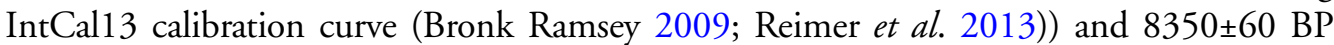
(7550-7290 cal BC to 95.4\%; date modelled in OxCal v.4.3, using IntCal13 calibration curve (Bronk Ramsey 2009; Reimer et al. 2013)) respectively.

This is the oldest burial at Hermitage and the earliest-known burial in Ireland. Pit B also contained cremated human remains dating to $8070 \pm 40 \mathrm{BP}(7090-7030 \mathrm{cal} \mathrm{BC}$ to $95.4 \%$; date modelled in OxCal v.4.3, using IntCal13 calibration curve (Bronk Ramsey 2009; Reimer et al. 2013)); the cremated bone in pit C (dated to $7610 \pm 40 \mathrm{BP}, 6610-6370 \mathrm{cal}$

\footnotetext{
PalaeoHub, Department of Archaeology, University of York, York YO10 5DD, UK

School of Archaeology, Newman Building, University College Dublin, Belfield, Dublin 4, Ireland

Egis Archaeology Ltd, 32 Nicholas Street, King's Island, Limerick, Ireland

Institute of Archaeology, University College London, London WC1H OPY, UK

Institute of Archaeology, University of Oxford, 36 Beaumont Street, Oxford OXI 2PG, UK

* Author for correspondence (Email: aimee.little@york.ac.uk)
}

(c) Antiquity Publications Ltd, 2019

ANTIQUITY 93 368, e8 (2019): 1-6

https://doi.org/10.15184/aqy.2019.32 


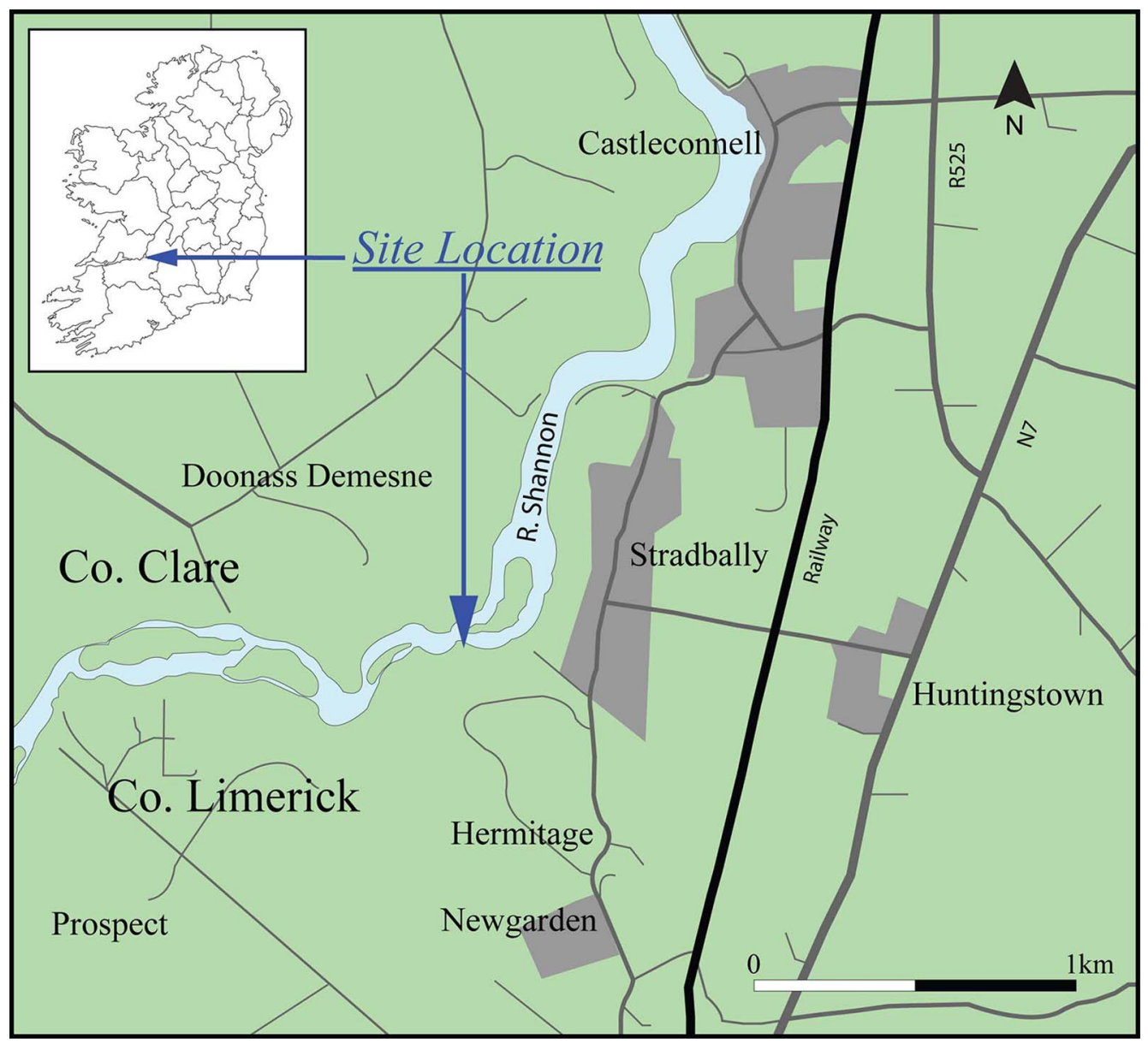

Figure 1. Map showing the location of Hermitage.

BC to 95.4\%; date modelled in OxCal v.4.3, using IntCal13 calibration curve (Bronk Ramsey 2009; Reimer et al. 2013)) could not be identified to species-level, but is probably also human. Ægis's excavations also produced archaeology relating to the Neolithic, Bronze Age and Iron Age at the site, suggesting the presence of a rich prehistoric landscape.

As part of a Marie Curie Postdoctoral Fellowship in 2015, the artefact assemblage from burial pit A was analysed for microwear and organic residue traces (Little et al. 2017). The results of this analysis (Figure 4) led to a reappraisal of human activity at Hermitage, and its relationship to both the Irish and wider European Mesolithic records. A technological study and experimental replication of the manufacturing process, demonstrated that the adze from burial pit $\mathrm{A}$ had been flaked and highly polished, representing a considerable investment of time. Microwear analysis revealed that it had been used, briefly, to chop wood, before being intentionally blunted. The adze was subsequently placed into the burial pit on top of the still-warm ashes of the deceased, leaning against a grave marker, before the pit was backfilled.

(C) Antiquity Publications Ltd, 2019 


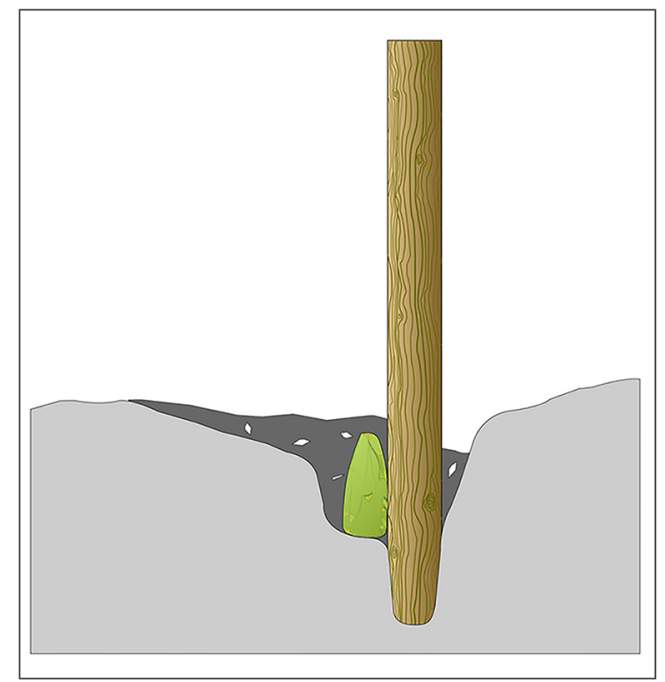

Figure 2. Reconstruction illustration of pit A cremation burial, showing the polished stone adze, cremation deposit and what was probably a wooden post grave marker.
Contextualising the discovery of this complex material expression of mortuary practice involved situating the early appearance of highly polished stone tools within the European Mesolithic, a rare instance of a Mesolithic cremation rite, and the extremely rare occurrence of multiple cremations at a single Mesolithic site. Closer scrutiny of the Hermitage radiocarbon dates suggested that cremation formed a long-lived mortuary practice on this particular bend of the Shannon. These findings, coupled with the untested potential for further cremations at the site, set up the tantalising possibility that Hermitage could once have been a hunter-gatherer cremation cemetery. This would be unprecedented within the European

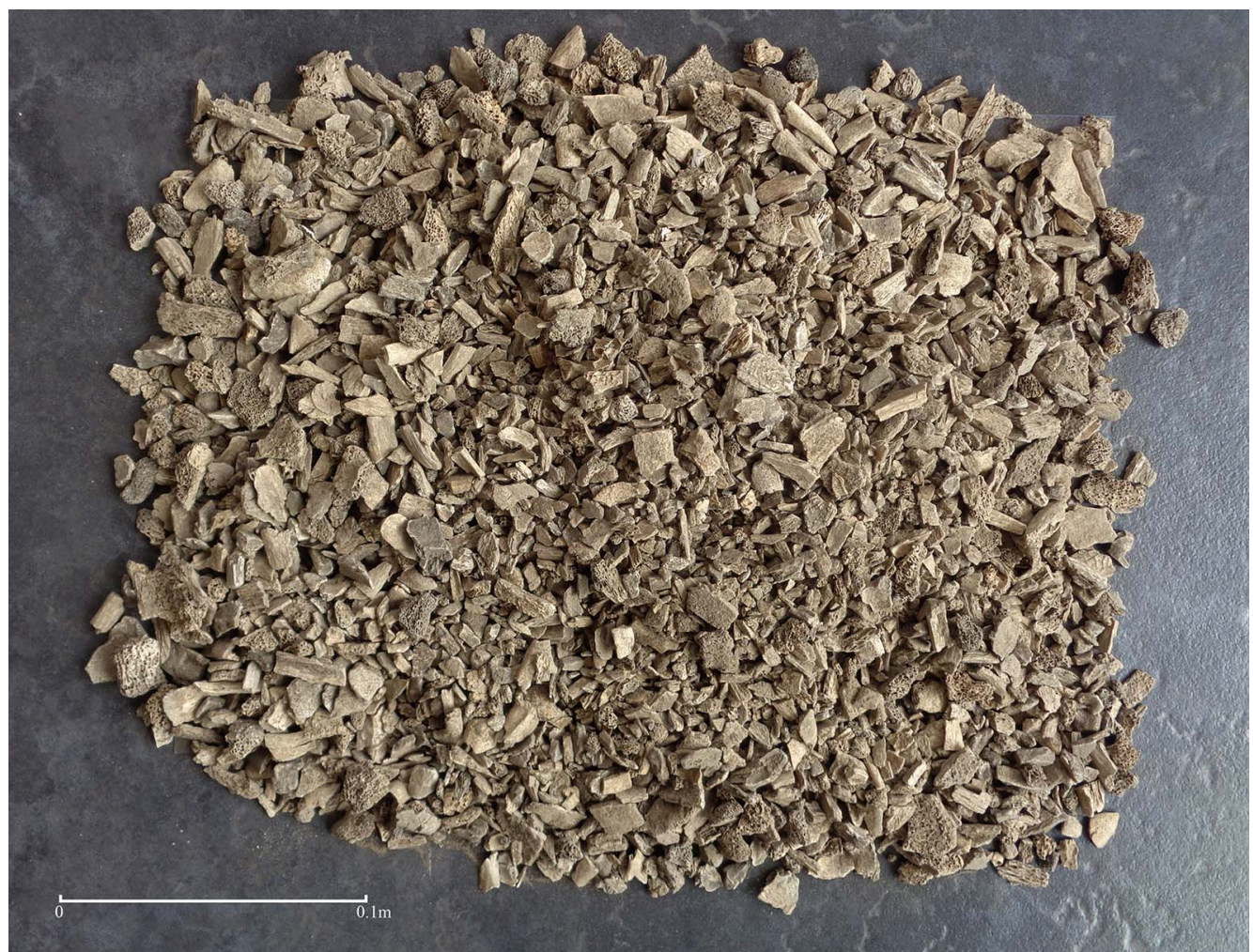

Figure 3. Well-cremated remains of complete adult, burial pit A (after Little et al. 2017).

(C) Antiquity Publications Ltd, 2019 


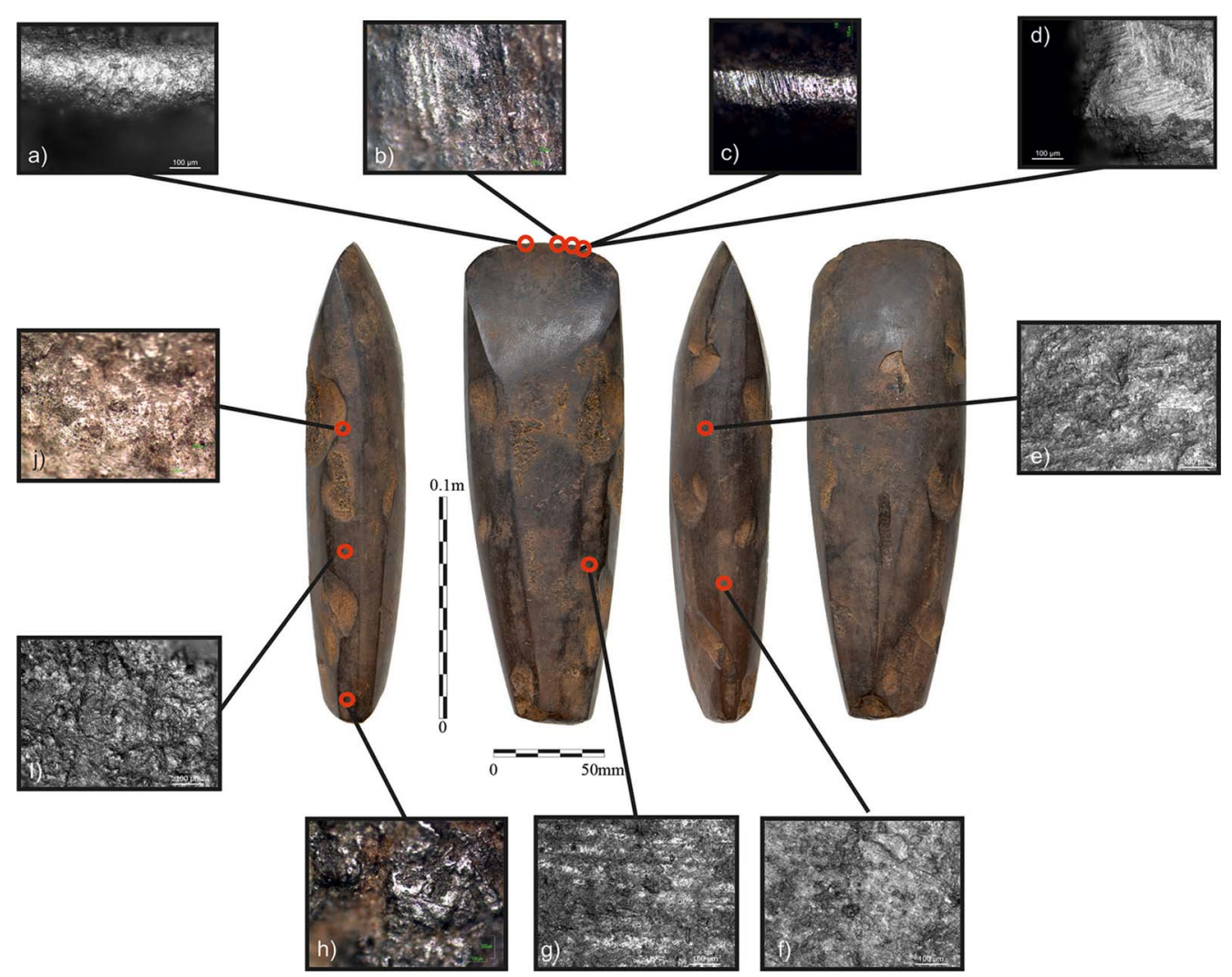

Figure 4. Polished adze from burial pit A: microwear analysis revealed the working edge was deliberately blunted prior to deposition (after Little et al. 2017).

archaeological record, offering a wealth of knowledge concerning the human societies who first inhabited the westernmost parts of Europe.

\section{H.A.R.P.}

In 2016, a team of researchers from Ireland and Britain met with the original excavators of the site to discuss the possibility of further archaeological investigations at Hermitage. The meeting involved discussion of the site's research potential, current challenges in understanding the archaeology of Hermitage, and a site visit and talk for the local historical association (Figure 5). The meeting was attended by a small group of researchers including experts in the analysis of cremated human remains, prehistoric material culture, the Mesolithic in Ireland, prehistoric cultural heritage management and the use of remote sensing in the investigation of early prehistoric landscapes. This meeting resulted in the formation of the Hermitage Archaeological Research Project (H.A.R.P.), and the development of a series of research questions that the project will address through further fieldwork at Hermitage:

1. What further well-preserved Mesolithic archaeology can be identified in the Hermitage landscape?

(C) Antiquity Publications Ltd, 2019 


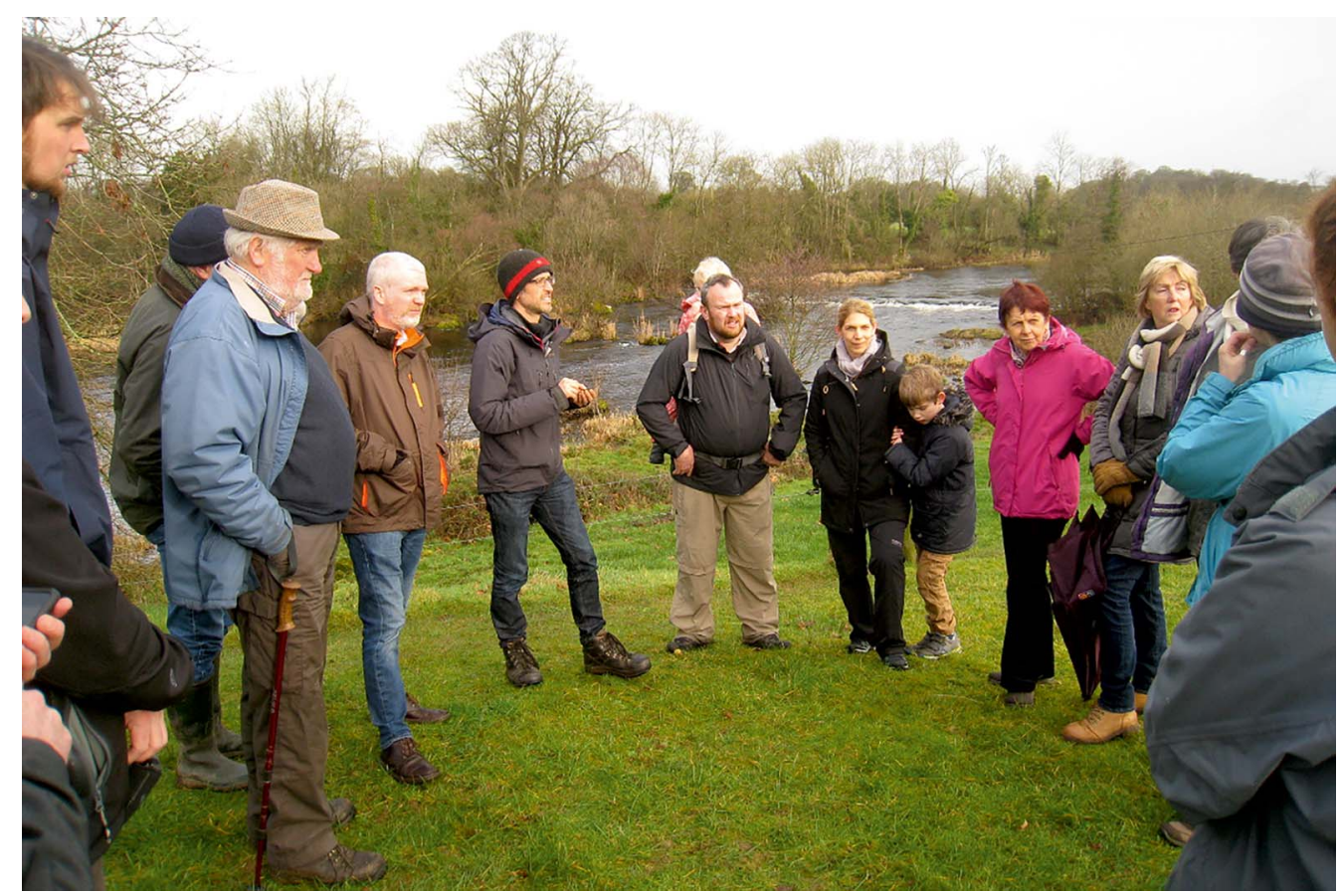

Figure 5. H.A.R.P. member Graeme Warren (centre left) talking to visitors from the local Castleconnell community at the location of one of the burials.

2. To what extent are deposits with high archaeological and palaeoenvironmental potential sealed by changing landscape processes?

3. What can we learn about the chronology and environment of Mesolithic Hermitage?

4. Are additional burials present?

With funding provided by the Royal Irish Academy, H.A.R.P. set about attempting to address these research questions through an initial geophysics and auger survey of the Hermitage site (Figure 6). This included employing a multi-technique approach specifically geared towards mapping and understanding the sediment sequences and landscape formation processes active at the site; methods used included fluxgate gradiometry, electrical conductivity and magnetic susceptibility. Survey work at other high-profile prehistoric sites in Britain and Ireland has established these methods as highly effective in developing a coherent picture of deposition and truncation at the landscape scale.

Desktop research and a conductivity survey identified interesting geomorphological features at the site; augering, undertaken alongside the geophysical survey, aimed to test the geoarchaeological potential of these features. This focused on areas of aquatic deposits, adjacent to the Shannon itself, and transects spanning the area of the 2001 excavation. Auger work identified potential areas for sampling. Examination of these samples will form the basis for further investigation including palaeoenvironmental analysis and test

(C) Antiquity Publications Ltd, 2019 


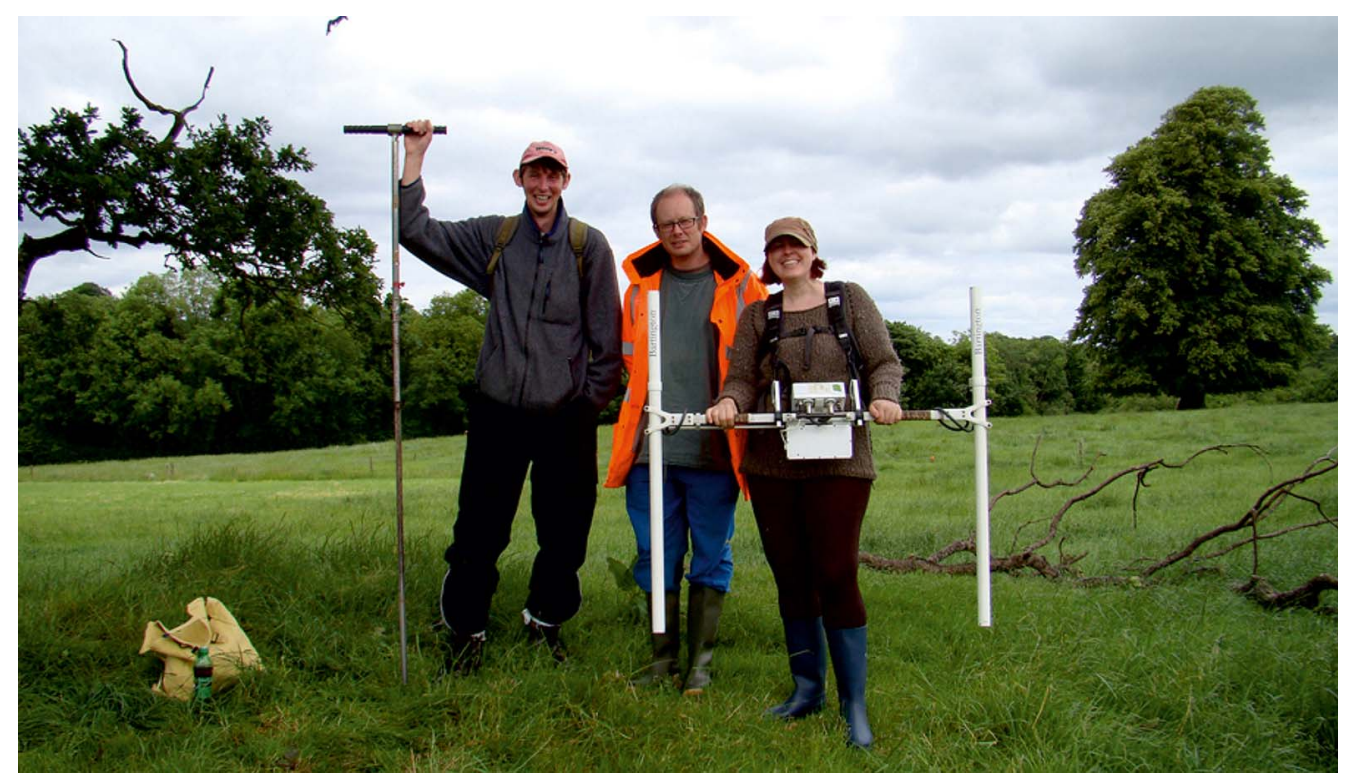

Figure 6. From left to right: H.A.R.P. team members Ben Elliott (UCD) and Ed Blinkhorn (UCL) with Helen Goodchild (University of York) carrying out field survey in 2018.

pitting of geophysical anomalies to ground truth emerging models of deposition and landscape formation.

\section{Acknowledgements}

H.A.R.P. has received funding from the Royal Irish Academy, The Heritage Council (Ireland) Community Heritage Grant Scheme and the University of York's Culture and Communication Research Theme. We would also like to thank the landowner for allowing us access to the site, and the Castleconnell Historical Society and local community for their continued support.

\section{References}

Bronk Ramsey, C. 2009. Bayesian analysis of radiocarbon dates. Radiocarbon 51: 337-60. https://doi.org/10.1017/S0033822200033865.

Collins, T. \& F. Coyne. 2003. Fire and water ...

Early Mesolithic cremations at Castleconnell, Co. Limerick. Archaeology Ireland 17(2): 24-27.

- 2006. As old as we felt. Archaeology Ireland 20(4): 21 .
Little, A., A. van Gijn, T. Collins, G. Cooney, B. Elliott, B. Gilhooly, S. Charlton \& G. WARREN. 2017. Stone dead: uncovering Early Mesolithic mortuary rites, Hermitage, Ireland. Cambridge Archaeological Journal 27: 223-43. https://doi.org/10.1017/S0959774316000536

Reimer, P.J. et al. 2013. IntCal13 and Marine13 radiocarbon age calibration curves $0-50,000$ years cal BP. Radiocarbon 55: 1869-87.

https://doi.org/10.2458/azu_js_rc.55.16947

Received: 23 November 2018; Accepted: 27 November 2018; Revised: 5 February 2019

(C) Antiquity Publications Ltd, 2019 